University of Wollongong

Research Online

Faculty of Engineering - Papers (Archive)

Faculty of Engineering and Information

Sciences

September 2006

\title{
THz Emission from Mercury Cadmium Telluride Films Grown on Cadmium Zinc Telluride Substrates
}

Rajind Mendis

University of Wollongong, rajind@uow.edu.au

M. L. Smith

University of Wollongong

R. E. Vickers

University of Wollongong, rv@uow.edu.au

R. A. Lewis

University of Wollongong, roger@uow.edu.au

C. Zhang

University of Wollongong, czhang@uow.edu.au

Follow this and additional works at: https://ro.uow.edu.au/engpapers

Part of the Engineering Commons

https://ro.uow.edu.au/engpapers/363

\section{Recommended Citation}

Mendis, Rajind; Smith, M. L.; Vickers, R. E.; Lewis, R. A.; and Zhang, C.: THz Emission from Mercury Cadmium Telluride Films Grown on Cadmium Zinc Telluride Substrates 2006.

https://ro.uow.edu.au/engpapers/363

Research Online is the open access institutional repository for the University of Wollongong. For further information contact the UOW Library: research-pubs@uow.edu.au 


\title{
THz Emission from Mercury Cadmium Telluride Films Grown on Cadmium Zinc Telluride Substrates
}

\author{
R. Mendis, M. L. Smith, R. E. M. Vickers, R. A. Lewis, and C. Zhang \\ Faculty of Engineering, University of Wollongong, Wollongong, NSW 2522, Australia \\ rajind@uow.edu.au
}

\begin{abstract}
We have observed $\mathrm{THz}$ emission from singleand double-layer $\mathrm{HgCdTe}$ (MCT) films epitaxially grown on CdZnTe substrates photoexcited by femtosecond laser pulses. The emitted $\mathrm{THz}$ radiation was electro-optically detected in reflection-mode at the $45^{\circ}$ specular direction. There is a dramatic variation in the emitted signal level from the double-layer samples, whereas the signal level from the single-layer samples shows a relatively constant variation with composition and/or geometry. For the double-layer samples, the highest peak amplitude recorded is 1/5 of that of an InAs emitter, analogous to double that of a standard ZnTe emitter, and shows promise for further enhancement.
\end{abstract}

\section{INTRODUCTION}

It is well known that unbiased semiconductor surfaces photoexcited by near-infrared femtosecond pulses can emit $\mathrm{THz}$ radiation (pulses) [1-3]. $\mathrm{THz}$ emission is attributed to the buildup of a transient photocurrent due to the surface-field and the differential carrier mobility or/and the buildup of a transient polarization due to the optical rectification effect [1]. Of all the unbiased surface-emitters examined to date, lightly-doped, $p$-type InAs has been found to be the strongest $[2,3]$. Recently, $\mathrm{Hg}_{1-\mathrm{x}} \mathrm{Cd}_{\mathrm{x}} \mathrm{Te}$ (MCT) has come under scrutiny [4], and here we present results of a study using a series of samples with single- and double-layer MCT films with varying composition and thickness, grown on $\mathrm{CdZnTe}$ substrates.

\section{RESULTS}

Fig. 1 shows the emitted peak signal amplitude, where circles represent double-layer samples (1 to 3 ), squares represent single-layer samples (4 to 6), and the diamond represents the substrate (7). There is a dramatic variation in the peak level for the double-layer samples, whereas it is relatively constant for the single-layer samples.

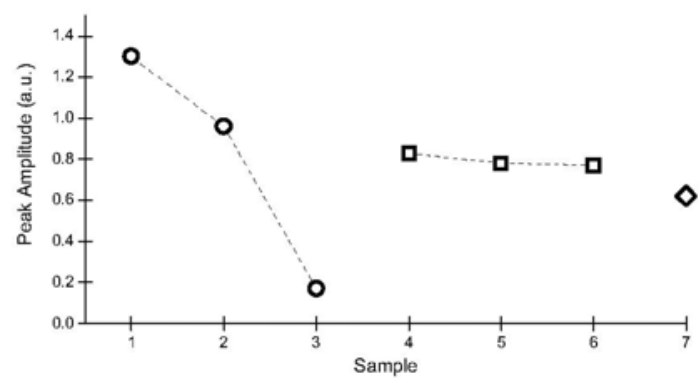

Figure 1. Relative performance.
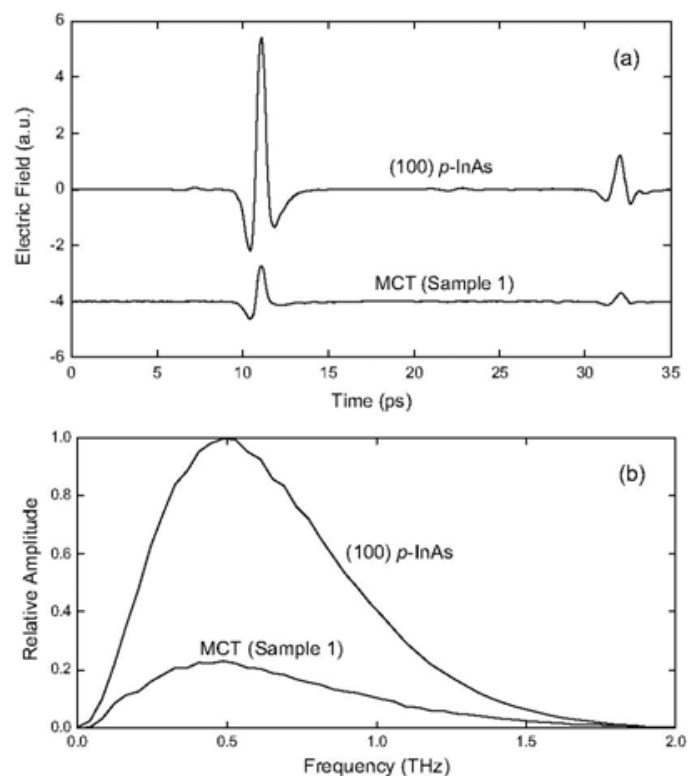

Figure 2. (a) THz signal from MCT sample compared to that from InAs, (b) and their amplitude spectra.

Fig. 2(a) gives the signal from sample 1, compared to that from an optimum InAs emitter. The MCT scan is vertically shifted for clarity. The secondary pulse seen after $21 \mathrm{ps}$ from the main is due to reflections from the detector-crystal. Fig. 2(b) gives the corresponding amplitude spectra obtained by Fourier transforming the isolated pulses. The signal from the MCT sample is $1 / 5$ that of InAs. Further enhancement is expected with different combinations of composition and geometry.

We thank L. Faraone and the Microelectronics Research Group of University of Western Australia for the provision of the samples.

\section{REFERENCES}

[1] P. Gu, M. Tani, S. Kono, K. Sakai, and X.-C. Zhang, "Study of terahertz radiation from InAs and InSb", J. Appl. Phys., vol. 91, pp. 5533-5537, 2002.

[2] K. Liu, J, Xu, T. Yuan, and X.C. Zhang, "Terahertz radiation from InAs induced by carrier diffusion and drift", Phys. Rev. B, vol. 73 , pp. $155330,2006$.

[3] R. Mendis, M. L. Smith, L. J. Bignell, R. E. M. Vickers, and R. A. Lewis, "Strong terahertz emission from (100) p-type InAs", J.Appl. Phys., vol. 98, pp. 126104, 2005.

[4] A. Krotkus, R. Adomavicius, G. Molis, A. Urbanowicz, and H Eusebe, "Terahertz radiation from $\mathrm{Cd}_{x} \mathrm{Hg}_{1 . x} \mathrm{Te}$ photoexcited by femtosecond laser pulses", J. Appl. Phys., vol. 96, pp. 4006-4008, 2004 